\title{
Radioastronomers make plans to protect Antarctica and the Moon
}

\section{Washington}

RADIOASTRONOMERS, worried that many of their telescopes may be blinded by interference from other users of the electromagnetic spectrum, are planning early action to keep Antarctica, the far side of the Moon and deep space in their present pristine condition.

At last week's International Astronomical Union meeting in Washington, DC, resolutions were passed calling for international regulations to preserve certain parts of the radio spectrum for scientific use alone and to ensure that places so far unaffected by growing civil and military radio technologies remain unspoiled.

Discussing the triple threat posed to astronomy by urban lighting, radio interference and debris in low Earth orbit, astronomers noted some success on the first and last issues. In their efforts to keep the night sky dark and space clear of junk, astronomers find few opponents. But in the web of international rules and committees that must be negotiated to obtain allocations of radio frequency usage, they are fighting an increasing number of competitors.

Frequency bands are allocated to various use categories, of which radioastronomy is one, by the International Telecommunications Union (ITU). ITU divides the world into three regions: the Americas; Europe, Africa and the Soviet Union; and Asia. But the biggest threat to radioastronomy is from global communication and navigation satellite networks, about which the old regional regulations say little, and from which Antarctica is not protected at all. So far, the South Pole is fairly free of radio interference, because few communication satellites operate in polar orbits, but astronomers want international regulations enacted to protect it in advance.
Around the rest of the world they are fighting a rearguard action now that all regions of the radio spectrum are under increasing pressure, and the frequency bands which used to be theirs by default have been encroached upon.

Although astronomers have few enemies, many of their competitors, which include international communications companies as well as various national governments, have economic and legislative power. The scientific community must therefore rely principally on persuasion. The Washington conference passed several resolutions asking for individual members and sympathetic governments to transmit astronomers' wishes to the International Radio Consultative Committee, which advises ITU on the competing needs of all radio users.

The conference also looked further into the future, at the feasibility of radioastronomy being done from the far side of the Moon or from the Lagrangian point L-2, a position of orbital stability beyond the Moon, which Soviet scientists have mentioned as an ideal site for a spacebased radio telescope. Until recently, anywhere beyond a line drawn through the centre of the Moon was considered deep space, and was heavily protected against radio use apart from frequency allocations for interplanetary probes. But recently the boundary of deep space was moved much further out, to two million $\mathrm{km}$ from Earth, bringing both the Moon and the $\mathrm{L}-2$ point under the control of the same regulations that apply to terrestrial and satellite transmissions. Radioastronomers would like to shrink the size of nearEarth space back to its old boundaries before the Moon too is taken away from them.

David Lindley

"International Astronomical Union. Colloquium 112 on "Light pollution, radio interference and space debris", 13-16 August 988.

\section{Active optics comes of age}

\section{Munich}

THE European Southern Observatory (ESO) has announced this month the successful testing of the $3.58-\mathrm{m}$ primary mirror for its New Technology Telescope (NTT), which is to go into operation in Chile early next year. The mirror, the first of its kind to be used in a telescope, relies on so-called 'active optics' to monitor and optimize the images continuously. The image quality a threefold improvement upon that of previous telescopes.

Researchers at ESO spent ten years developing active optics, which use 75 mobile and 3 fixed supports beneath the mirror to control its shape. A microcomputer running a special algorithm is all that is required to control the feedback loop between the mirror and an image analyser. Only by slightly bending the

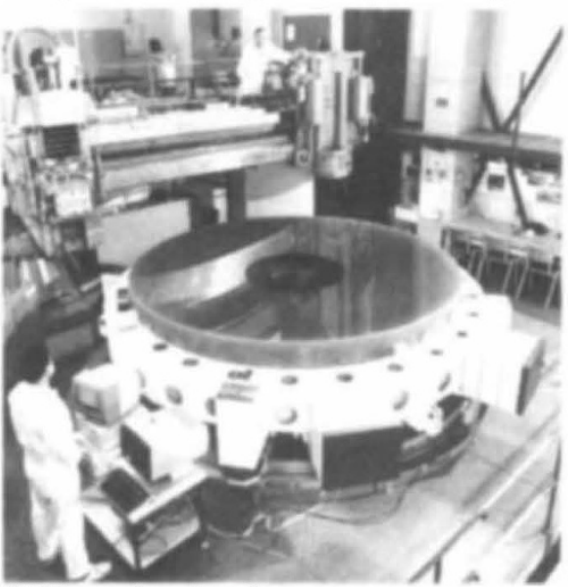

ESO's see-by-wire mirror.

mirror in a controlled way can the highest resolutions be achieved.

The mirror, which cost DM6 million, was made from a glass-ceramic blank at the West German firm Schott and polished at Carl Zeiss in Oberkochen, West Germany. At $24 \mathrm{~cm}$ in thickness, the blank is much thinner than a normal blank but still stable enough to provide decent images without active optics.

Active-optics technology is likely to play a significant role in the next generation of optical telescopes. Traditional, inflexible mirrors larger than $5 \mathrm{~m}$ in diameter tend to deform under their own weight, as astronomers in the Soviet Union have learned the hard way in attempting to build a 6-m telescope.

ESO's Very Large Telescope, an array of four 8-m telescopes to be built in Chile in the 1990s, will rely on active optics to manoeuvre mirrors even thinner than the NTT's. Researchers at Japan's Tokyo Astronomical Observatory plan a 7.6-m telescope using active optics to be constructed, probably in Hawaii, in the early $1990 \mathrm{~s}$.

Steven Dickman 